\title{
Promoção da interculturalidade a partir dos manuais escolares de Português
}

\author{
Promoting intercultural education through textbooks of Portuguese language
}

\author{
João Paulo Balula*, Sara Pinho**, Susana Amante* \\ * CI\&DETS - Instituto Politécnico de Viseu - ESEV, ** Instituto Politécnico de Viseu - ESEV
}

\begin{abstract}
Resumo
A importância, cada vez maior, dos esforços para assegurar o respeito pela diferença torna pertinente avaliar o contributo dos manuais escolares de Português na promoção da interculturalidade. Neste trabalho, discutem-se alguns resultados do estudo, de natureza multimetodológica, que partiu da análise de dois manuais escolares de Português ( $4 .^{\circ}$ ano) para uma intervenção didática numa turma do mesmo ano de escolaridade. Os resultados obtidos mostram que as propostas de atividades promotoras do pensamento reflexivo sobre interculturalidade são escassas nos manuais escolares analisados e indicam que a atuação do professor é determinante para promover o entendimento mútuo e o respeito pelo Outro.
\end{abstract}

Palavras-chave: Interculturalidade, Manuais escolares de Português, Educação Literária, Educação para a cidadania global.

\begin{abstract}
The growing importance of efforts to ensure respect for issues of difference calls for the evaluation of the contribution of textbooks of Portuguese in the promotion of interculturality. In this paper, we discuss some results of a multi-methodological research that was based on the analysis of two textbooks of Portuguese (4th grade) to implement didactic interventions in a class of the same grade level. The results show that the activities promoting critical thinking about interculturality are scarce in the textbooks analysed and indicate that the role of the teacher is substantial in promoting mutual understanding and respect for the Other

Keywords: Interculturality, Textbooks of Portuguese language, Literary Education, Education for global citizenship.
\end{abstract}

\section{Introdução}

Os textos literários apresentam-se, cada vez mais, como um espaço privilegiado de desenvolvimento da interculturalidade. A par disso, nos últimos anos, temos assistido a uma multiplicação de esforços no sentido de assegurar o respeito pelas diferenças e a valorização da diversidade humana. No contexto educativo português, as orientações programáticas e os normativos legais em vigor têm contribuído para que os manuais escolares e as práticas pedagógicas se comprometam com a promoção de uma sociedade intercultural. Assim, o presente estudo tem como objetivo analisar a articulação existente entre o quadro legislativo e a prática das instituições, tendo em vista uma efetiva educação intercultural, e verificar até que ponto os recursos didáticos disponíveis e a legislação em vigor têm reduzido ou reproduzido assimetrias e contrastes, com repercussões na realidade socioeconómica portuguesa. Para o efeito, analisamos dois manuais escolares certificados para o $4 .^{\circ}$ ano do ensino básico (incluindo os guiões de leitura e as fichas de trabalho para os alunos que fazem parte dos mesmos projetos editoriais), de modo a aferirmos qual a importância e o tratamento que conceitos como diferença, igualdade e interculturalidade recebem a propósito do trabalho com narrativas da Lista de Obras e Textos para a Educação Literária, em particular O Gato e o Escuro e O Beijo da Palavrinha, da autoria de Mia Couto. A esta análise seguiu-se a implementação de uma intervenção didática destinada a trabalhar o texto $O$ Beijo da Palavrinha numa turma do $4 .^{\circ}$ ano de escolaridade. Neste estudo foi adotada uma metodologia mista. $\mathrm{Na}$ primeira fase do estudo, foi feita a análise de conteúdo das propostas didáticas para a leitura das duas obras de Literatura Africana de Expressão Portuguesa apresentadas pelos manuais escolares de duas editoras. Na segunda fase do estudo, foi analisada a informação recolhida a partir da aplicação, à turma da intervenção didática, de um questionário destinado a avaliar a evolução da perspetiva dos participantes sobre os valores da interculturalidade. Os resultados do estudo indicam que, muito embora os manuais escolares em análise não cumpram cabalmente o esperado relativamente à educação intercultural, já que apresentam poucas atividades que estimulem o pensamento reflexivo sobre esta problemática, a atuação do professor é determinante como agente de transformação, na mudança de atitudes rumo ao entendimento mútuo e ao respeito.

\section{Os manuais escolares e a promoção da interculturalidade}

Considerando os objetivos enunciados, e atendendo ao facto de as práticas letivas assentarem, em grande parte, no trabalho proposto nos manuais escolares, torna-se imperativa a análise do corpus de textos literários que integram este recurso didático-pedagógico e que potenciam um diálogo intercultural. Cientes de que analisar todos os textos que permitem uma educação promotora da interculturalidade seria empreitada por demais ambiciosa, até porque as próprias orientações programáticas e os normativos legais em vigor preveem 
o respeito pela diferença, como aduziremos de seguida, reportar-nos-emos, na nossa análise, a dois textos do moçambicano Mia Couto que constam da Lista de Obras e Textos para a Educação Literária para o 4. ${ }^{\circ}$ ano do ensino básico.

$\mathrm{Na}$ verdade, vivemos, atualmente, num mundo que se quer cada vez mais cosmopolita, fruto das transformações sociais, económicas, políticas e culturais conducentes a uma globalização que, espera-se, não aniquile os traços distintivos da identidade de um povo. Como nos lembra Claude Lévi-Strauss, citado por Taylor, Brander, Cardenas, Gomes e Vicente Abad " $[t] h e$ discovery of others is the discovery of a relationship, not of a barrier" (2004, p. 41). Assim, o convívio entre o Eu e o Outro num espaço comum implica a abertura à diferença e o reconhecimento mútuo, o que, por sua vez, é favorecido por uma preocupação crescente com uma educação inclusiva e intercultural, preocupação essa que se concretiza em princípios orientadores emanados pelo Ministério da Educação e Ciência.

Embora as diligências no sentido de assegurar o espaço educativo da diferença tenham eclodido sobretudo no século XXI, esse cuidado começou a fazer-se sentir ainda no final do século XX, aquando da publicação da Lei de Bases do Sistema Educativo (Lei n. ${ }^{\circ}$ 46/86, de 14 de outubro, com as alterações introduzidas pela Lei n. ${ }^{\circ}$ 115/97, de 19 de setembro, e, mais tarde, pela Lei n. ${ }^{\circ}$ 49/2005, de 30 de agosto), que estabelece, no artigo $3 .^{\circ}$, os seguintes princípios organizativos:

a) Contribuir para a defesa da identidade nacional e para o reforço da fidelidade à matriz histórica de Portugal, através da consciencialização relativamente ao património cultural do povo português, no quadro da tradição universalista europeia e da crescente interdependência e necessária solidariedade entre todos os povos do Mundo; b) Contribuir para a realização do educando, através do pleno desenvolvimento da personalidade, da formação do carácter e da cidadania, preparando-o para uma reflexão consciente sobre os valores espirituais, estéticos, morais e cívicos e proporcionando-lhe um equilibrado desenvolvimento físico; c) Assegurar a formação cívica e moral dos jovens; d) Assegurar o direito à diferença, mercê do respeito pelas personalidades e pelos projetos individuais da existência, bem como da consideração e valorização dos diferentes saberes e culturas.

Não é, pois, de estranhar que a legislação em torno dos manuais escolares tenha sofrido reflexos destas preocupações, como bem o evidencia a circular $n .^{\circ}$ 7/2000, de 4 de abril, que destaca a importância da educação para a cidadania, quando salienta que “o manual escolar (...) contribui também, através de valores que explícita ou implicitamente veicula, para a formação cívica e democrática dos alunos”.

Na primeira década do século XXI, o Programa de Português do Ensino Básico, não descurando esta tendência, aponta, no domínio das competências gerais, para, de entre outros, o "eixo da experiência humana, onde se situa a tensão entre a individualidade e a comunidade, com os correspondentes procedimentos de integração...” (Reis et al., 2009, p. 13).

Mais recentemente, as Metas Curriculares de Português vieram especificar, através da criação do domínio da Educação Literária,

uma lista de obras e textos literários para leitura anual, válida a nível nacional, garantindo assim que a escola, a fim de não reproduzir diferenças socioculturais exteriores, assume um currículo mínimo comum de obras literárias de referência para todos os alunos que frequentam o Ensino Básico. (Buesco, Morais, Rocha \& Magalhães, 2012, p. 6)

Não obstante este currículo mínimo comum de obras literárias de referência integre, em maior número, autores recentes do universo da literatura infanto-juvenil nacional, observa-se a partir do $4 .^{\circ}$ ano de escolaridade um corpus literário um pouco mais eclético, o que abre portas ao reconhecimento da diferença como espaço de diálogo e de negociação.

Significará esta asserção que os manuais escolares, nas propostas de atividades que apresentam sobre os textos da lista para Educação Literária, cumprem tais propósitos? De acordo com o Decreto-Lei n. ${ }^{\circ}$ 14788-A/2013, de 14 de novembro, os manuais escolares, para serem certificados, devem atender ao “[R]igor linguístico, científico e conceptual”; apresentar "[c]onformidade com os programas e orientações curriculares"; revelar "[q]ualidade didáctico-pedagógica”; observar os critérios de "[r]eutilização e adequação ao período de vigência previsto e, no âmbito dos “[v]alores”, “[r]espeitar os valores e os direitos e deveres fundamentais consagrados na Constituição", de entre outros. Crê-se, portanto, que os manuais escolares deverão satisfazer os requisitos mínimos no que respeita a assuntos sobre identidade e respeito pela alteridade, embora tal não seja necessariamente sinónimo de promoção de valores interculturais, dado que os manuais, como faremos notar no decurso da nossa análise, podem tão simplesmente alhear-se da responsabilidade de formar cidadãos críticos e comprometidos com uma sociedade que reconhece as diferenças individuais como naturais, positivas e produtivas.

Quem não se alheia de tais responsabilidades, em Portugal, é a Direção-Geral da Educação, pois em 2012 apresentou um documento intitulado Educação para a Cidadania - linhas orientadoras, que estabelece várias dimensões para o exercício de práticas educativas que deverão conceber-se como um "processo participado, individual e coletivo, que apela à reflexão e à ação sobre os problemas sentidos por cada um e pela sociedade" (2012, p. 1). De entre as diferentes dimensões, destacamos a "educação para os direitos humanos", a “educação para a igualdade de género”, a "educação intercultural” e a “dimensão europeia da educação”, pela sua relevância e pelo ajustamento com os objetivos por nós traçados. Afunilando ainda mais esta nossa seleção, importa lançarmos um olhar sobre a Educação Intercultural que, segundo o mesmo documento,

pretende promover o reconhecimento e a valorização da diversidade como uma oportunidade e fonte de aprendizagem para todos, no respeito pela multiculturalidade das sociedades atuais. Pretende-se desenvolver a capacidade de comunicar e incentivar a interação social, criadora de identidades e de sentido de pertença comum à humanidade. (DGE, 2012, p. 5) 
A educação intercultural é, pois, um trabalho pedagógico que envolve vários intervenientes, desde o Ministério da Educação e Ciência, passando pelas editoras, professores e ainda pais/encarregados de educação e alunos. Em termos específicos, o professor, em articulação com as famílias, tem um papel fundamental na criação de oportunidades de diálogo e de coexistência pacífica entre o Eu e o Outro. A interpretação e uso que faz dos referenciais, dos manuais escolares e de outros materiais didáticos é determinante para que se veicule um discurso que fomente o respeito e dignificação do ser humano ou, pelo contrário, para que, mesmo involuntariamente, se promovam preconceitos e discriminações.

Se é certo que, em variadíssimas circunstâncias, os professores delegam nos manuais escolares e respetivos materiais de apoio o trabalho a realizar com os alunos, por os assumirem como a materialização dos referenciais e orientações curriculares, bem como depositários de valores intelectuais, morais e estéticos, não o é menos que os professores são, não raras vezes, profissionais que fazem a diferença ao lidar com questões da diferença e da identidade, particularmente ao estimularem o pensamento crítico, como Henry Giroux (1996) sublinha: If educators are to take the relationship between schooling and democracy seriously, this means organizing school life around a version of citizenship that educates students to make choices, think critically, and believe that they can make a difference. (p. 298)

O próprio aluno deve consciencializar-se do papel decisivo que detém nas relações interpessoais e intergrupais, uma vez que, em última instância, ele é o cidadão de hoje e do futuro, um futuro que está nas mãos de cada um e que se quer construir também além-fronteiras.

\section{Metodologia}

Este estudo, de natureza multimetodológica, partiu da análise de dois manuais escolares de Português ( $4 .^{\circ}$ ano) com vista à conceção e implementação de uma intervenção didática numa turma do mesmo ano de escolaridade.

\section{Participantes}

Participaram neste estudo 19 alunos (13 alunos do sexo masculino e 6 alunos do sexo feminino) de uma turma do $4 .^{\circ}$ ano de escolaridade do concelho de Viseu - Portugal, com idades compreendidas entre os 9 e os 10 anos. A escolha dos participantes, intencional e de conveniência, assentou no facto de os manuais de Português do $4 .^{\circ}$ ano serem os mais relevantes para o estudo da temática dos valores da interculturalidade, ao mesmo tempo que o nível de compreensão em leitura dos alunos dá algumas garantias para a realização do estudo.

\section{Materiais}

Foram utilizados dois manuais escolares de Português (4. ${ }^{\circ}$ ano), dois questionários, dois livros de Mia Couto $(O$ Gato e o Escuro; O Beijo da Palavrinha) e um plano de uma Intervenção Didática.

\section{Procedimento}

O estudo centrou-se na análise de conteúdo sobre dois manuais escolares certificados para o $4 .^{\circ}$ ano do ensino básico (incluindo os guiões de leitura e as fichas de trabalho para os alunos que fazem parte dos mesmos projetos editoriais), centrada nas propostas didáticas para a leitura das duas obras de Literatura Africana de Expressão Portuguesa apresentadas pelos manuais escolares de duas editoras. Na segunda fase do estudo foi analisada a informação recolhida a partir da implementação de uma intervenção didática que incluiu a aplicação de dois questionários destinados a avaliar a evolução da perspetiva dos participantes sobre os valores da interculturalidade.

\section{Análise e discussão dos resultados}

1. O manual escolar "é transmissor de valores afetivos, estéticos, sociais, intelectuais e espirituais. (...) Qualquer obra transmite algo ao leitor e os alunos não são alheios a esta influência, quer seja positiva ou negativa” (Brito, 1999, p. 145). Por conseguinte, apresentamos, de seguida, o resultado de um olhar sobre as duas narrativas de Mia Couto que, na nossa perspetiva, são exímias na configuração do espaço identitário, embora, simultaneamente, apelem à possibilidade de transgressão de fronteiras e à construção de comunidades de diálogo.

Na obra $O$ gato e o escuro (Couto, 2001), o autor convida o leitor a superar as suas próprias fronteiras simbólicas e a olhar, a partir do seu interior, para o horizonte onde pode alcançar o Outro, independentemente da sua aparência ou da sua marca geográfico-temporal. É uma narrativa que permite a leitura de um Eu que se coloca no campo da alteridade, mediante uma experiência de transposição de limites impostos.

Pintalgato, o protagonista desta narrativa, quer cortar com o preconceito em relação ao escuro e, dessa forma, construir um autoconceito. Ao conhecer o escuro, que neste caso representa o Outro, o gato desenvolve um pensamento positivo sobre ele, mas através da experiência que teve no decorrer da narrativa.

Nesta história, há uma transformação do mundo para o tornar melhor, mais tolerante e respeitador das diferenças. No decorrer desta narrativa, o gato completou uma aprendizagem essencial que foi o reconhecimento do valor do Outro. Esse é, nas palavras de Mia Couto, o principal objetivo de $O$ gato e o escuro:

espero que o gatinho que habita estas páginas possa afastar ideias escuras que temos sobre o escuro. A maior parte dos medos que sofremos, crianças e adultos, foi fabricada para nos roubar curiosidade e para matar a vontade de querer saber o que existe além do horizonte. (Garcia, 2012, s/p)

Já na obra O beijo da palavrinha (Couto, 2008), pode encontrar-se o reconhecimento do Outro em duas personagens: na Maria Poeirinha (personagem principal da história) e no seu irmão Zeca Zonzo.

Podemos reconhecer o Outro na personagem Maria Poeirinha, pois ela é uma criança diferente por estar doente, às portas da morte, sendo, por conseguinte, vítima de um destino que lhe rouba a sua infância. Apesar de estar no leito da morte, Maria Poeirinha não 
abdica do mundo dos sonhos nem da imaginação querendo, mesmo assim, "ver" o mar, por se acreditar que este poderia ser sinónimo de esperança e salvação.

Como referido, também é na personagem Zeca Zonzo que encontramos a representação do Outro, isto porque, apesar de ser caracterizado como "desprovido de juízo" (Couto, 2008, p. 1), é ele que encontra uma solução para levar a sua irmã a "ver" o mar antes de falecer. Salienta-se que, apesar do Outro ser diferente (neste caso, “desprovido de juízo”), devemos valorizá-lo, pois todos podemos aprender uns com os outros.

Aquando do aparecimento da doença de Maria Poeirinha, o Tio Jaime Litorâneo afirma que, para a menina se curar, tem de fazer a travessia do mar. Contudo, essa travessia seria impossível, de forma literal, em virtude da fragilidade do seu corpo e, por conseguinte, com ajuda do irmão Zeca Zonzo, a protagonista encontra uma maneira distinta de "ver" esse mar e, dessa interação, surgem novas significações sobre si e sobre a vida.

Maria Poeirinha, não podendo sair para ver o mar, em virtude da sua debilidade física, consegue fazer a tão necessária travessia pelas mãos, pela voz e pela intervenção criativa do seu irmão, Zeca Zonzo.

Para concluir, tal como nos diz Medeiros, "[e]ntre mãos e voz, a palavra escrita é a canoa a transportar a menina para além dos limites do espaço em que vivia, a fazê-la abrir os olhos para dentro e ver possibilidades e sonhos inéditos” (2013, s/p). Também Mia Couto nos transporta a nós, leitores, para além dos limites do espaço em que vivemos e nos faz abrir os olhos para vermos além de nós mesmos.

As narrativas em apreço surgem nos manuais em análise. Os dois manuais foram escolhidos pelas seguintes razões: o primeiro é o manual que foi adotado pela escola na qual decorreu a intervenção didática, enquanto o segundo serviu como termo de comparação por conter a outra obra de Mia Couto.

Ao analisarmos cuidadosamente os manuais, verificamos que, no que concerne ao primeiro manual, as atividades de compreensão de leitura a respeito do conto O Gato e o Escuro evitam, de uma forma geral, abordar aspetos relacionados com os valores da interculturalidade e com conceitos como diferença e igualdade. $\mathrm{Na}$ nossa perspetiva, as tarefas de acompanhamento relacionadas com o texto, designadas por “compreensão leitora”, não ajudam as crianças a desenvolverem o seu pensamento crítico sobre esta temática, pois uma abordagem acrítica não pode pedir um olhar crítico e, portanto, não implica a capacidade de envolver as crianças criticamente no mundo, acreditando que a mudança é possível. Este manual poderia fazer melhor uso do texto de Mia Couto, a fim de oferecer às crianças a possibilidade de se envolverem no reconhecimento da importância do respeito para com o Outro e da promoção da diversidade.

Por outro lado, o segundo manual permite que os alunos tenham a perspetiva do que é respeitar a diferença através da leitura de excertos de $O$ Beijo da Palavrinha, em que se convidam os discentes a pensar em maneiras pelas quais eles poderiam resolver o problema de Maria Poeirinha. Além disso, incentiva-os a reconhecer as diferenças linguísticas entre estes dois países de língua portuguesa: "Mia Couto (...) é moçambicano e escreve em português. Pede ajuda ao teu professor e identifica no texto algumas expressões que não comuns no português de Portugal".

Também no livro "Fichas de Leitura - Educação Literária” do mesmo manual, podemos verificar que as questões que lá se encontram apelam ao pensamento crítico das crianças e a que estas vejam o Outro como algo positivo e com quem se pode aprender: "O texto diz que Zeca Zonzo era «desprovido de juízo». Concordas com esta afirmação? Justifica a tua resposta” e "Apesar de os pais terem dito a Zeca Zonzo para ele poupar o irmão «daquela tontice» de lhe mostrar o mar, ele não desistiu da ideia. Achas que o Zeca Zonzo fez bem ou mal? Justifica a tua resposta”.

Tendo em especial atenção a Meta Curricular EL4.25, "Ler para apreciar textos literários de Educação Literária”, em que um dos objetivos é “manifestar sentimentos e ideias suscitados por histórias e poemas ouvidos” (Buesco, Morais, Rocha \& Magalhães, 2012, p. 32), torna-se necessário que os livros didáticos promovam o pensamento crítico das crianças, a sua reação moral à experiência humana e a articulação de tudo isso tanto com o poder de contar histórias como com o conhecimento pessoal.

2. Após uma análise cautelosa das obras e dos manuais escolares selecionados, foram aplicados dois questionários à turma em estudo para se poder ter uma perspetiva sobre aquilo que os alunos pensavam sobre alguns valores relativos ao interculturalismo.

Os dois questionários eram constituídos por duas partes: a primeira era formada por duas questões de resposta fechada e dizia respeito aos dados de caracterização pessoal dos inquiridos; a segunda era constituída por questões de escolha múltipla. Contudo, numa das opções, os inquiridos tiveram a possibilidade de responder abertamente sobre o que pensam. De notar que as várias questões tinham itens abertos para justificar opções.

Depois da aplicação do primeiro questionário e da análise das respostas obtidas, foi implementada uma intervenção didática, constituída por três sessões, baseada na exploração no texto $O$ beijo da palavrinha. No final da intervenção, foi aplicado um segundo questionário.

As respostas ao questionário revelaram que os inquiridos já apresentam uma postura de tolerância e respeito face à diferença. Contudo, as respostas ao segundo questionário corroboram mais vincadamente esta ideia. Então vejamos: na questão sobre o que é a igualdade, verifica-se que, no segundo questionário, 63\% dos inquiridos dizem que a igualdade é estar aberto(a) à diversidade cultural e respeitá-la. Depois da intervenção didática, houve mais inquiridos a responder que a igualdade era estar aberto(a) à diversidade cultural e respeitá-la do que antes da intervenção (58\%). A diferença maior centra-se nas restantes percentagens, ou seja, no primeiro questionário, verifica-se que $32 \%$ dos inquiridos referiram que a igualdade é sermos todos iguais. Porém, no segundo, observamos que apenas 11\% 
afirmaram o mesmo, havendo uma descida de 21\%. Em contrapartida, $26 \%$ dos inquiridos no segundo questionário responderam que a igualdade é valorizar as ideias do Outro. Confrontando esta percentagem com a do primeiro questionário, pode-se constatar que subiu $16 \%$.

Relativamente às respostas sobre o que é a diferença, verifica-se que, no segundo questionário, $89 \%$ dos inquiridos responderam que a diferença é algo positivo e que nos pode enriquecer como pessoas. Confrontando esta percentagem com a do primeiro questionário, nota-se que houve uma subida, visto que, no primeiro questionário, apenas $74 \%$ dos inquiridos responderam dessa forma. No segundo questionário, apenas $11 \%$ responderam que a diferença é algo que devemos excluir, enquanto no primeiro esta percentagem era de $26 \%$.

No que se refere à questão "A forma como perspetivas o Outro mudou ao longo das últimas aulas?”, verificou-se que mais de metade dos inquiridos (53\%) mudou o modo como perspetiva o Outro, pois afirmam que antes não valorizavam as ideias do Outro e, com as últimas aulas, aprenderam a valorizá-las até o menos inteligente pode ter ideias melhores que os inteligentes. Um outro inquirido afirma que foi através da obra $O$ Beijo da Palavrinha que mudou a sua maneira de perspetivar o Outro. Contudo, a diferença de percentagens é muito reduzida entre os que afirmam ter mudado a sua perspetiva de ver o Outro e os que afirmam não ter mudado. Essa diferença mínima, talvez se deva ao facto dos que afirmam não ter mudado a sua maneira de ver o Outro serem os que já perspetivavam a diferença como algo positivo e enriquecedor.

No segundo questionário, foi perguntado aos alunos se achavam que a escola constituía um contexto importante para a aprendizagem e para o exercício de valores de interculturalismo. Verificou-se que $95 \%$ afirmaram que sim e disseram que só através da escola sabem o que pensam e fazem outras culturas, porque nas aulas se fala da importância de sermos todos diferentes. Dizem ainda que a escola aceita pessoas de culturas diferentes, a escola ensina as crianças a serem cidadãos, a respeitar tudo e todos e a valorizar as ideias dos outros.

Por fim, verificou-se que $68 \%$ dos inquiridos consideram que os manuais escolares promovem o reconhecimento e a valorização da diversidade.

\section{Considerações finais}

Os resultados da análise dos manuais e da informação recolhida na intervenção didática indicam que, muito embora os manuais escolares não cumpram cabalmente o esperado no que se refere à educação intercultural, já que apresentam poucas atividades que estimulem o pensamento reflexivo sobre esta problemática, a atuação do professor é determinante como agente de transformação, na mudança de atitudes rumo ao entendimento mútuo e ao respeito. A intervenção didática baseada nas orientações programáticas e nos vários referenciais disponíveis na escola portuguesa possibilitam a promoção da interculturalidade, através da educação literária, e a educação para a cidadania global.

\section{Referências}

Amante, S., Pinho, S., \& Balula, J. P. (2015, March). Textbooks as a basic resource for the promotion of intercultural coexistence? - A case study. Paper presented at "8th Global Conference: Interculturalism, Meaning and Identity”, Lisbon. Obtido de http://hdl.handle.net/10400.19/2847

Brito, A. P. (1999). A problemática da adopção dos manuais escolares: critérios e reflexões. In R. V. Castro, A. Rodrigues, J. L. Silva, \& M. L. Sousa (Orgs.), Manuais escolares: estatuto, funções, história (pp 139-148). Braga: Lusografe.

Buescu, H. C., Morais, J., Rocha, M. R., \& Magalhães, V. F. (2012). Metas Curriculares de Português. Ensino básico. $1 .^{\circ}, 2^{\circ}$ e $3 .^{\circ}$ ciclos. Lisboa: Direção-Geral da Educação.

Couto, M. (2001). O gato e o escuro. Lisboa: Editorial Caminho.

Couto, M. (2008). O beijo da palavrinha. Alfragide: Editorial Caminho.

DGE - Direção-Geral da Educação (2012). Educação para a Cidadania: Linhas Orientadoras, atualizado em novembro de 2013. Lisboa: Ministério da Educação.

Garcia, N. K. (2012). Mia Couto e uma história contra o medo. Obtido de http://www.wwlivros.com.br/IIjornadaestlit/artigos/po rt_bras/GARCIANeivaKampff.pdf

Giroux, H. (1996). Educational Visions: What are Schools for and What Should we be Doing in the Name of Education? In J. Kincheloe \& S. Steinberg (eds.), Thirteen Questions: Reframing Education's Conversations. New York: Peter Lang.

Letra, C. \& Borges, M. (2013). O Mundo da Carochinha, Português Gailivro 4. Alfragide: Edições Gailivro.

Lima, E., Barrigão, N., Pedroso, N. \& Rocha, V. (2013). Alfa 4 - Português. Porto: Porto Editora.

Medeiros, C. B. (2013). O voo da gaivota branca: A representação da morte em o beijo da palavrinha. Revista eletrônica de estudos literários. 2 (13). Obtido de periodicos.ufes.br/reel/article/download/6173/4511

Rego, B., Gomes, C., \& Balula, J. P. (2012). A avaliação e certificação de manuais escolares em Portugal: Um contributo para a excelência. In M. F. Patrício, L. Sebastião, J. M. Justo, \& J. Bonito (Orgs.). Da Exclusão à Excelência: Caminhos Organizacionais para a Qualidade da Educação, (pp. 129-138). Montargil: AEPEC.

Reis, C. et al (2009) (org.) Programa de português do ensino básico. Lisboa: Ministério da Educação / Direção Geral de Inovação e Desenvolvimento Curricular.

Taylor, M., Brander, P., Cardenas, C., Gomes, R., Vicente Abad, J. (2004). Education Pack: Ideas, Resources, Methods and Activities for Informal Intercultural Education with Young People and Adults, 2nd ed. Strasbourg: Council of Europe Publishing. 